\title{
Membranous nephropathy associated with thrombospondin type-1 domain-containing 7A (THSD7A) in an adult woman with eosinophilia
}

\author{
Sayuri Shirai ${ }^{1}$ - Shin'ichi Akiyama ${ }^{2} \cdot$ Atsuko Kamijo-Ikemori $^{3} \cdot$ Tomo Suzuki $^{4} \cdot$ Daisuke Ichikawa $^{5} \cdot$ Junki Koike $^{6}$. \\ Kenjiro Kimura $^{7} \cdot$ Yugo Shibagaki $^{5}$
}

Received: 12 September 2019 / Accepted: 20 October 2019 / Published online: 8 November 2019

(c) The Author(s) 2019

\begin{abstract}
A 30-year-old woman on steroid therapy for eosinophilia presented with nephrotic syndrome during steroid tapering. She was diagnosed with membranous nephropathy (MN) stage II-III (positive for IgG1 and IgG4) by renal biopsy. There was no evidence of secondary MN. Her urinary protein level was controlled to $0.5 \mathrm{~g}$ /day or less, and her eosinophil count in white blood cell differential was stabilized at less than $10 \%$ without increasing the steroid dosage. The renal specimen did not show any enhanced granular expression of PLA2R along the glomerular basement membrane, and PLA2R was not detected in the patient's serum. On retrospective analysis, enhanced granular staining for thrombospondin type-1 domain-containing 7A (THSD7A) in the glomeruli was detected in the biopsy, and anti-THSD7A IgG was detected in the serum using a commercial indirect immunofluorescence test (IFT). Based on these, the case was considered as THSD7A-associated MN with comorbid eosinophilia. The causal relationship between THSD7A-related MN and eosinophilia was unclear. However, a few cases of THSD7A-associated MN with eosinophilia have been reported, and further clarification on the relationship between THSD7A-related MN and eosinophilia is warranted.
\end{abstract}

Keywords Membranous nephropathy $\cdot$ Eosinophilia $\cdot$ THSD7A $\cdot$ PLA2R

Sayuri Shirai

sirababu@marianna-u.ac.jp

1 Division of Nephrology and Hypertension, Department of Internal Medicine, St. Marianna University School of Medicine Yokohama City Seibu Hospital, 1197-1 Yasashi-cho, Asahi-ku, Yokohama 241-0811, Japan

2 Division of Nephrology, Department of Internal Medicine, Nagoya University Graduate School of Medicine, 65 Tsurumai-cho, Showa-ku, Nagoya 466-8550, Japan

3 Department of Anatomy, St. Marianna University School of Medicine, 2-16-1 Sugao, Miyamae-ku, Kawasaki 216-8511, Japan

4 Department of Nephrology, Kameda Medical Center, 929 Higashicho, Kamogawa 296-8602, Japan

5 Division of Nephrology and Hypertension, Department of Internal Medicine, St. Marianna University School of Medicine, 2-16-1 Sugao, Miyamae-ku, Kawasaki 216-8511, Japan

6 Department of Diagnostic Pathology, St. Marianna University School of Medicine, 2-16-1 Sugao, Miyamae-ku, Kawasaki 216-8511, Japan

7 Division of Nephrology, Department of Internal Medicine, Tokyo Takanawa Hospital, 3-10-11 Takanawa, Minato-ku, Tokyo 108-8606, Japan

\section{Introduction}

Membranous nephropathy (MN), a common nephrotic syndrome in adults, is caused by immune complex deposition in the subepithelial area of the glomerular basement membrane and the subsequent activation of the complement system. About 20\% of MNs are secondary MNs that present along with malignant tumors, drug reactions, collagen diseases, and infectious diseases; and most of them are idiopathic.

Recently, it was reported that M-type phospholipase A2 receptor 1 (PLA2R) and thrombospondin type-1 domaincontaining 7A (THSD7A) are two of the causative antigens of idiopathic MN (IMN) [1, 2]. The prevalence of PLA2Rassociated $\mathrm{MN}$ and THSD7A-associated $\mathrm{MN}$ were reported to be $80-85 \%$ and $3-5 \%$, respectively [3]; in Japan, they are $50-70 \%$, and $3-10 \%$, respectively [4]. Iwakura et al. reported that $60 \%$ of women with THSD7A-associated MN were diagnosed before the age of 40 years [5].

Recent studies have also shown a possible relationship between THSD7A-associated MN and cancer [6, 7]. Hoxha et al. screened serum samples of 1276 patients with MN from three different cohorts for the presence of THSD7A-Ab 
using a newly developed indirect immunofluorescence test (IFT) and showed that the new test had $92 \%$ sensitivity and $100 \%$ specificity. Twenty percentage of the patients with THSD7A-associated MN in their cohort also had a malignant disease, while only $7 \%$ with PLA2R1-associated MN presented with cancer [6]. However, other causes of THSD7A-associated MN remains unknown. Recently, there have been a few reports of THSD7A-associated MN that were complicated by allergic diseases [8-10]. The credibility of this association requires assessment; however, we have experienced similar cases firsthand.

Here, we report a case of THSD7A-associated MN with comorbid eosinophilia. THSD7A was detected in the glomeruli by immunohistochemistry on frozen kidney biopsy samples. In addition, anti-THSD7A IgG in the serum was detected using a commercial indirect IFT. Our findings indicate the necessity to examine the relationship between allergic diseases and THSD7A antibody generation.

\section{Case report}

A 30-year-old woman, in March X-1 year, after wisdom tooth extraction, manifested bilateral arthralgia, swelling of lower legs and forearms, and pain on Achilles tendon sticking area. She visited a primary care clinic, where her blood test showed an increase in WBC count and was referred to a city hospital. Her WBC count was $20,710 / \mu \mathrm{L}$; eosinophils $10,562 / \mu \mathrm{L}(51 \%)$. Urine examination reported protein, $1+$, and occult blood, 1+. WBC increase had not been detected during screening. She had a history of pediatric asthma and allergic rhinitis. She had no prior infection and no history of oral supplements. She was negative for C-reactive protein (CRP), rheumatoid factor (RF), antinuclear antibody (ANA), and antineutrophil cytoplasmic antibody (ANCA). Her chest X-ray was normal. Based on these observations, she was diagnosed with eosinophilia and was transferred to the rheumatology clinic in our institute at the end of March $\mathrm{X}-1$ year. At that time, her blood and urine examinations showed the following: WBC, 15,400/ $\mu \mathrm{L}$; eosinophils, 4774/ $\mu \mathrm{L}(31 \%)$; serum IgE, $530 \mathrm{IU} / \mathrm{mL}$; urine protein, $3+$; and urine occult blood, $1+$. The patient was administered 15-mg oral prednisolone (PSL) for eosinophilia; the dose was gradually reduced. After PSL administration, her blood and urine examination showed remission of proteinuria and normal eosinophil count; however, after decreasing PSL dose to $4 \mathrm{mg}$, her urinary protein increased to over $1 \mathrm{~g} / \mathrm{g} \mathrm{Cr}$.

She underwent emergency surgery for appendicitis in December X-1 year (at that time, the PSL dosage was $4 \mathrm{mg}$ ). About a month after the surgery, she became aware of edema in the lower limbs, and by February X year her weight increased by $3-5 \mathrm{~kg}$. Her proteinuria increased to $8.9 \mathrm{~g} / \mathrm{g} \mathrm{Cr}$ in March 2010.
A kidney biopsy was performed in May $\mathrm{X}$ year. Table 1 shows the laboratory data at the time of renal biopsy. At that time, eosinophils were suppressed by the steroid treatment. There were focal segmental spike formations in Periodic acid methenamine (PAM) staining (Fig. 1b). Granular IgG deposits along the capillary basement membrane (Fig. 2) were identified by immunofluorescence microscopy (IF). Codominant staining of IgG1 and IgG4 (Fig. 3) was observed. Electron microscopy classified the subepithelial deposits as stage II $\sim$ III (Fig. 4).

Next, we used an anti-PLA2R antibody to screen for the PLA2R antigen responsible for MN. Immunofluorescence imaging of a renal specimen did not show enhanced granular expression of PLA2R along the glomerular basement membrane (Fig. 5a). PLA2R was not detected in the patient's serum by western blotting (Fig. 6a left). Based on the above results, we initially diagnosed the condition as IMN However, a protein with a molecular weight higher than that of PLA2R was detected by western blot (Fig. 6a right).

As the proteinuria spontaneously improved, PSL dosage was maintained at $4 \mathrm{mg}$. An incomplete remission (urine protein $<1 \mathrm{~g} / \mathrm{g} \mathrm{Cr}$ ) was attained in about half a year. From October X year, PSL dosage was reduced to $3 \mathrm{mg}$. After that, PSL dosage was reduced more gradually; PSL was discontinued in March $\mathrm{X}+5$ years; the proteinuria dropped to less than $1 \mathrm{~g} / \mathrm{g}$ Cr. The patient was maintained on irbesartan, and aliskiren and the proteinuria further dropped to $0.5 \mathrm{~g} / \mathrm{g} \mathrm{Cr}$. The eosinophil count was also stabilized at less than $10 \%$ and was maintained at a slightly higher average of 5.6\% with PSL $4 \mathrm{mg}$ /day or less. (Fig. 7).

In the meantime, THSD7A was identified as the second antigen responsible for IMN in $\mathrm{X}+4$ years. We retrospectively identified the heavier band detected by western blotting as THSD7A, which was supported by the following findings: enhanced granular staining for THSD7A in the glomeruli in a biopsy specimen (Fig. 5b), and detection of anti-THSD7A IgG in the serum using a commercial indirect IFT (Fig. 6b). Based on these, we diagnosed this case as THSD7A-associated MN.

\section{Discussion}

Autoantibodies against podocyte antigen, thrombospondin type-1 domain-containing 7A (THSD7A), have been reported to be responsible for primary $\mathrm{MN}$; but, it remains uncertain how these antigens are recognized by the immune system.

In the present case, WBC and eosinophil count increased at the same time as reactive arthritis, so it cannot be denied that reactive arthritis caused the eosinophil increase [11]. There was a history of allergic rhinitis and childhood asthma as well as an underlying allergic predisposition. We 
Table 1 Laboratory data of the patient (under steroid treatment) at the time of renal biopsy

\begin{tabular}{llll}
\hline Complete blood count & & Serology & \\
WBC & $9.9 \times 10^{3} / \mu \mathrm{L}$ & $\mathrm{C} 3$ & $88 \mathrm{mg} / \mathrm{dL}$ \\
Eosinophils & $5.6 \%$ & $\mathrm{C} 4$ & $17 \mathrm{mg} / \mathrm{dL}$ \\
$\mathrm{Hb}$ & $13.1 \mathrm{~g} / \mathrm{dL}$ & $\mathrm{IgG}$ & $540 \mathrm{mg} / \mathrm{dL}$ \\
$\mathrm{Plt}$ & $40.9 \times 10^{4} / \mu \mathrm{L}$ & $\mathrm{IgA}$ & $106 \mathrm{mg} / \mathrm{dL}$ \\
Blood chemistry & & $\mathrm{IgM}$ & $249 \mathrm{mg} / \mathrm{dL}$ \\
$\mathrm{T}-\mathrm{bil}$ & $1.0 \mathrm{mg} / \mathrm{dL}$ & $\mathrm{IgE}-\mathrm{RIST}$ & $330 \mathrm{IU} / \mathrm{ml}$ \\
$\mathrm{AST}$ & $12 \mathrm{IU} / \mathrm{L}$ & $\mathrm{RF}$ & $(-)$ \\
$\mathrm{ALT}$ & $10 \mathrm{IU} / \mathrm{L}$ & ANA & $(-)$ \\
$\mathrm{ALP}$ & $144 \mathrm{IU} / \mathrm{L}$ & $\mathrm{MPO}-\mathrm{ANCA}$ & $<10 \mathrm{EU}$ \\
$\mathrm{LDH}$ & $169 \mathrm{IU} / \mathrm{L}$ & $\mathrm{PR} 3-\mathrm{ANCA}$ & $<10 \mathrm{EU}$ \\
$\mathrm{TP}$ & $4.6 \mathrm{~g} / \mathrm{dL}$ & $\mathrm{Urine}$ analysis & \\
$\mathrm{Alb}$ & $2.8 \mathrm{~g} / \mathrm{dL}$ & Protein & $3.2 \mathrm{~g} / \mathrm{gCr}$ \\
$\mathrm{BUN}$ & $7.7 \mathrm{mg} / \mathrm{dL}$ & $\mathrm{NAG}$ & $13.5 \mathrm{U} / \mathrm{L}$ \\
$\mathrm{Cr}$ & $0.49 \mathrm{mg} / \mathrm{dL}$ & $\mathrm{RBC}$ & $1-4 / \mathrm{HPF}$ \\
$\mathrm{eGFR}$ & $117.9 \mathrm{~mL} / \mathrm{min} / 1.73 \mathrm{~m}^{2}$ & WBC & $10-19 / \mathrm{HPF}$ \\
$\mathrm{UA}$ & $7.4 \mathrm{mg} / \mathrm{dL}$ & & \\
$\mathrm{Na}$ & $139 \mathrm{mEq} / \mathrm{L}$ & & \\
$\mathrm{K}$ & $4.2 \mathrm{mEq} / \mathrm{L}$ & & \\
$\mathrm{Cl}$ & $111 \mathrm{mEq} / \mathrm{L}$ & & \\
$\mathrm{CRP}$ & $<0.03 \mathrm{mg} / \mathrm{dL}$ & & \\
$\mathrm{HbA} 1 \mathrm{C}$ & $4.6 \%$ & & \\
\hline
\end{tabular}

$R B C$ red blood cell count, $W B C$ white blood cell count, $H b$ hemoglobin, Plt platelet, $T$-bil total bilirubin, $A S T$ aspartate aminotransferase, $A L T$ alanine aminotransferase, $A L P$ alkaline phosphatase, $L D H$ lactic dehydrogenase, $T P$ total protein, $A l b$ albumin, $B U N$ blood urea nitrogen, $C r$ creatinine, $U A$ uric acid, $C R P$ C-reactive protein, $C 3$ complement component 3, $C 4$ complement component 4, Ig immunoglobulin, $R F$ rheumatoid factor, $A N A$ antinuclear antibodies, $A N C A$ antineutrophil cytoplasmic antibody, $M P O$ - myeloperoxidase-, $P R 3$ - protease 3-, $N A G \mathrm{~N}$-acetyl- $\beta$-D-glucosamidase speculate that reactive arthritis may have developed due to some kind of trigger after the dental treatment. A renal biopsy was performed 1 year and 2 months after the onset of eosinophilia. There was no eosinophil infiltration in the kidney tissue, probably because the eosinophil count of 1500/ $\mu \mathrm{L}$ or more did not last long enough under steroid treatment. The time when the urinary abnormality was observed coincided with the onset of eosinophilia; suggesting that eosinophilia and $\mathrm{MN}$, which were later diagnosed, may have been present since then. Proteinuria in the nephrotic range appeared when the steroid dose was reduced from 15 to $4 \mathrm{mg}$, and the pre-existing MN may have been exacerbated due to the stress of surgery for appendicitis, as supporting evidence, the stage of MN was 2-3.

In 2014, Tomas et al. reported THSD7A, a type I membrane protein $(250 \mathrm{kDa})$ expressed in the glomerular epithelial cells, as a new endogenous antigen of human MN [2]. An immunofluorescence examination of the renal specimen from our patient showed an enhanced granular expression of THSD7A along the glomerular basement membranes. Additionally, we confirmed THSD7A positivity by western blotting and indirect IFT for anti-THSD7A IgG detection. We have recently recognized this case as THSD7A-associated
MN. However, we had recognized a single band whose molecular weight was higher than that of PLA2R in the patient's serum by western blotting before Tomas et al.'s report [2] was published.

There are several reports of MN complicated with eosinophilia [12-14]. Although the relationship between eosinophilia and $\mathrm{MN}$ is not clear, several immunological mechanisms are conceivable. It has been reported that the immunological background of $\mathrm{MN}$ patients has superiority to Th2 [15] and that Th2 cytokines induce IgG4 synthesis [16]. Meanwhile, it is known that Th2 cytokines are produced by natural killer cells, eosinophils, and mast cells, in addition to Th2 cells. It has been speculated that viral infections or toxins may stimulate the release of lymphokines by altering $\mathrm{T}$ cell immunoregulation. These immunological triggers could result in associated renal lesions $[13,17]$. Regarding the relationship between eosinophilia and THSD7A-associated MN, Matsumoto et al. presented two cases of THSD7A-associated MN accompanied by ALHE, a benign tumor characterized by the proliferation of plump endothelial cells [8]. They found that in ALHE, eosinophils expressed vascular endothelial growth factor-A (VEGF-A), which upregulated THSD7A 


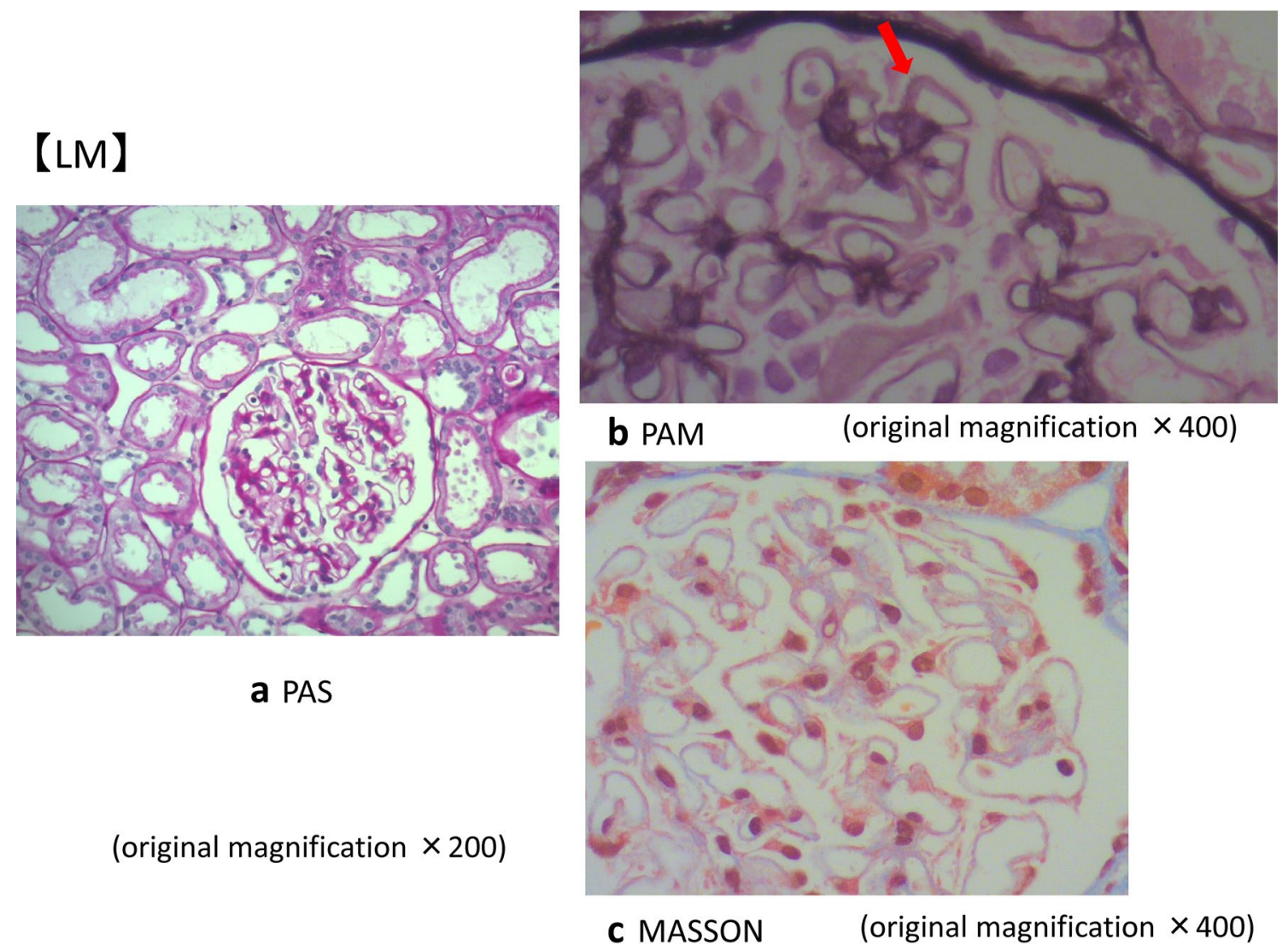

Fig. 1 Micrographs showing glomeruli in the kidney. a Periodic acidSchiff (PAS) staining of the renal biopsy specimen showing a minor glomerular abnormality. Original magnification $\times 200$. b Periodic acid methenamine silver (PAM) staining showing focal segmental

expression, especially under Th2-prone conditions in cultured human umbilical vein endothelial cells (HUVEC). Their results showed that VEGF-A-induced THSD7A expression outside the kidney might be necessary for MN pathogenesis. Furthermore, Suzuki et al. reported a case of THSD7A-MN with refractory asthma and eosinophilia and suggested that THSD7A-MN may be associated with severe asthma and eosinophilia [9]. In this case, THSD7Aassociated $\mathrm{MN}$ is thought to have occurred coincidentally with eosinophilia, but it cannot be completely denied that eosinophilia caused THSD7A-associated MN. It could be considered that eosinophilia caused some endothelial cell injury, which induced THSD7A, as stated in previous reports. $[8,9]$. Recently, Hara et al. reported that among 469 consecutive cases of pathologically confirmed MN spike formations (red arrow). Original magnification $\times 400$. $\mathbf{c}$ Masson trichrome staining showing granular immune complex along the glomerular basement membrane. Original magnification $\times 400$

diagnosed by THSD7A tissue staining of renal biopsy specimens at four centers in Japan, 14 cases were confirmed positive for THSD7A by immunohistochemistry (3.0\%), and four patients had concurrent or previous incidence of allergic diseases, including one patient with Kimura's disease [10].

In summary, we report a case of THSD7A-associated $\mathrm{MN}$ in an adult woman with eosinophilia diagnosed by serum antibody testing as well as THSD7A staining in a renal biopsy. Only a few cases of allergic disease such as eosinophilia complicated with THSD-related MN have been reported, and details regarding its relevance are unknown. Further investigation based on a nationwide disease registry is required to understand the relationship between THSD7Arelated $\mathrm{MN}$ and eosinophilia. 


\section{【IF】}
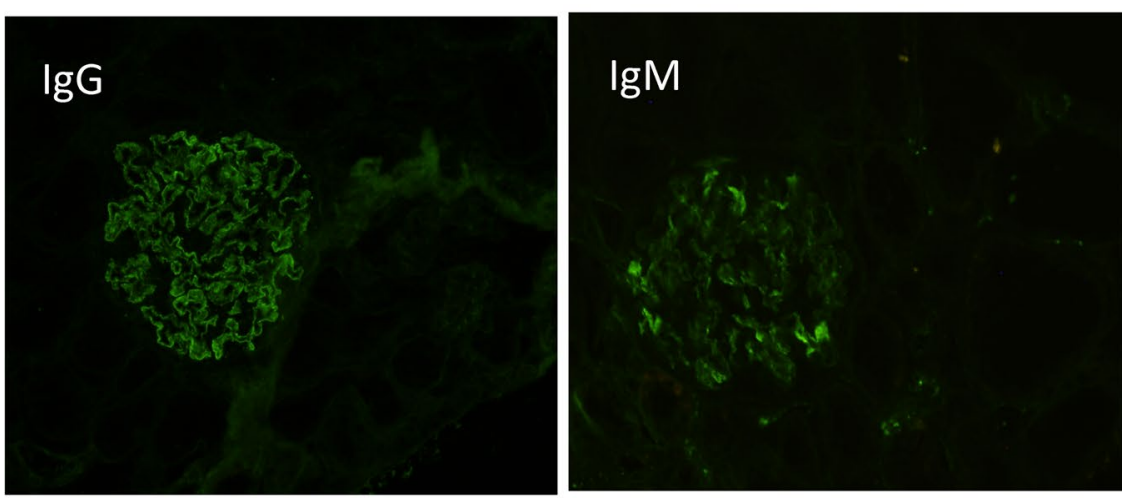

$\lg \mathrm{A}$
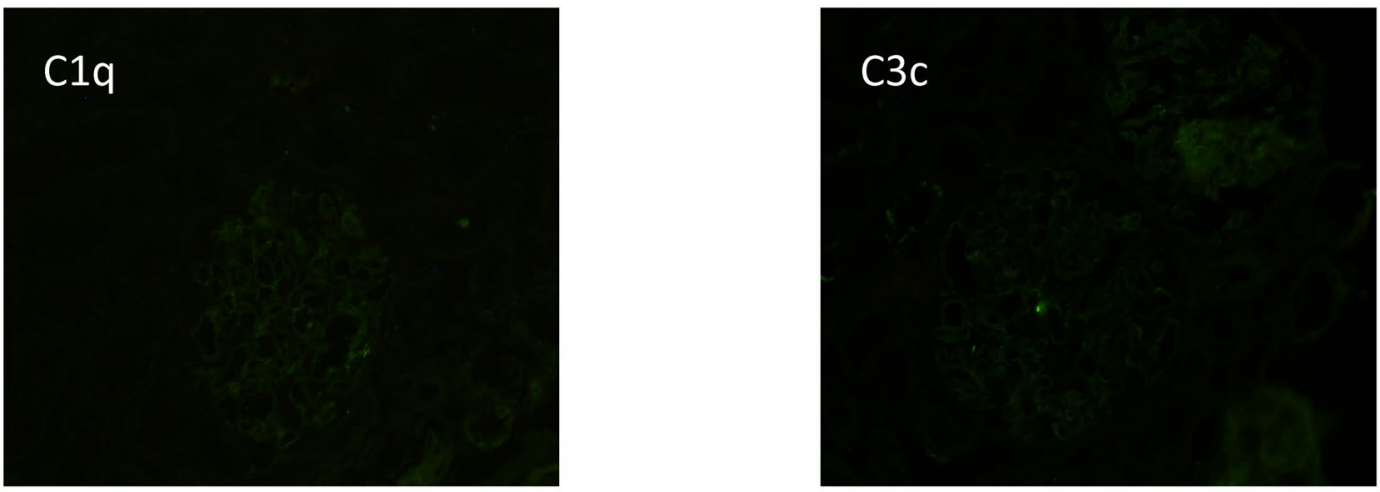

(original magnification $\times 200$ )

Fig. 2 Immunofluorescence microscopy (IF). IF image of the renal specimen showing granular $2+$ capillary wall staining for IgG, $1+$ capillary wall staining for IgM. No staining for IgA, C1q, C3c. Original magnification $\times 200$

Fig. 3 IgG subclass staining in IF IgG1 and IgG4 IF image of the renal specimen showing granular $2+$ capillary wall staining for IgG1 and IgG4. No staining was observed for IgG2 and IgG3. Original magnification $\times 200$

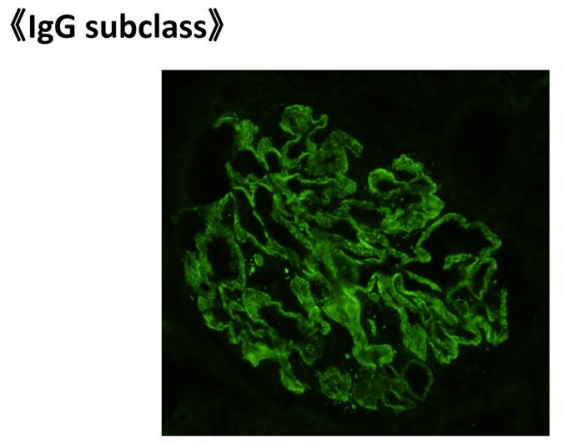

$\lg G 1$

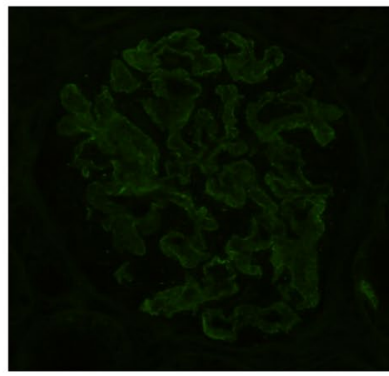

$\lg G 3$

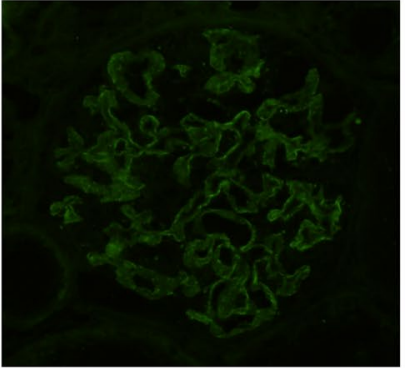

$\lg G 2$

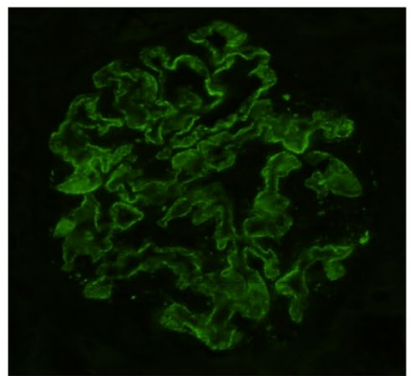

$\operatorname{lgG4}$

(original magnification $\times 400$ ) 


\section{【EM】}

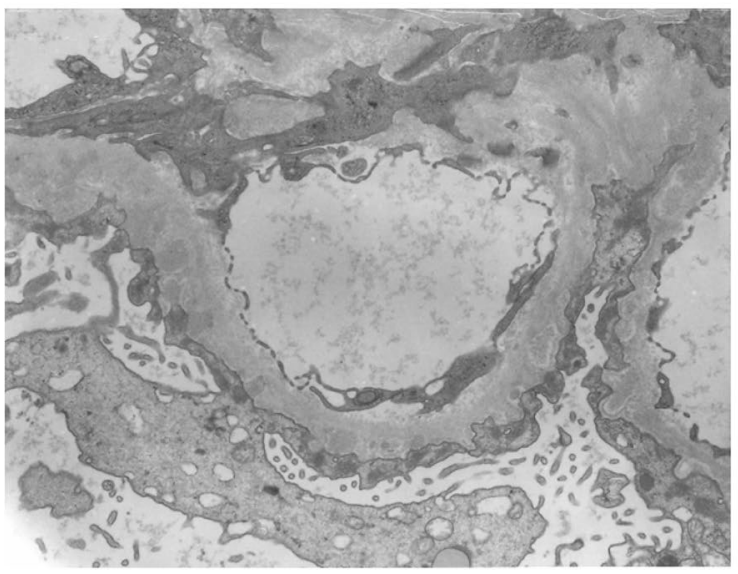

(original magnification $\times 5,000$ )

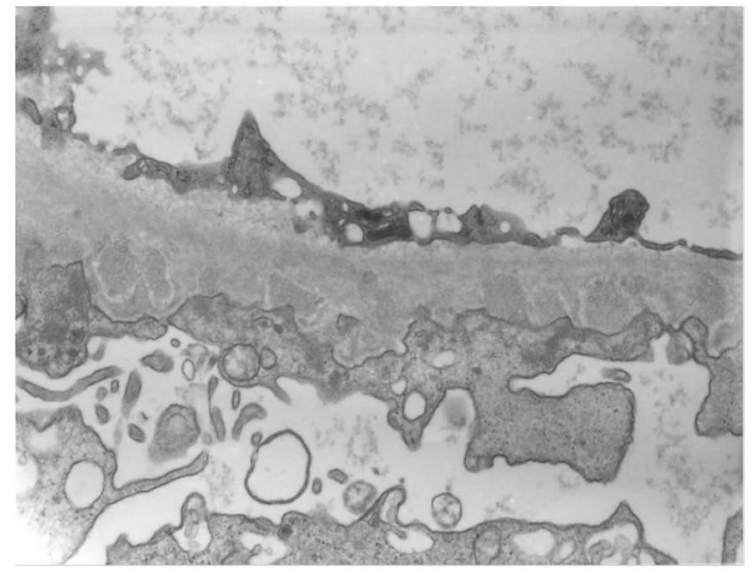

(original magnification $\times 10,000$ )

Fig. 4 Electron microscopy (EM). EM image of the renal specimen revealed subepithelial deposits in the glomerular basement membrane. Original magnification $\times 5000$ and $\times 10,000$

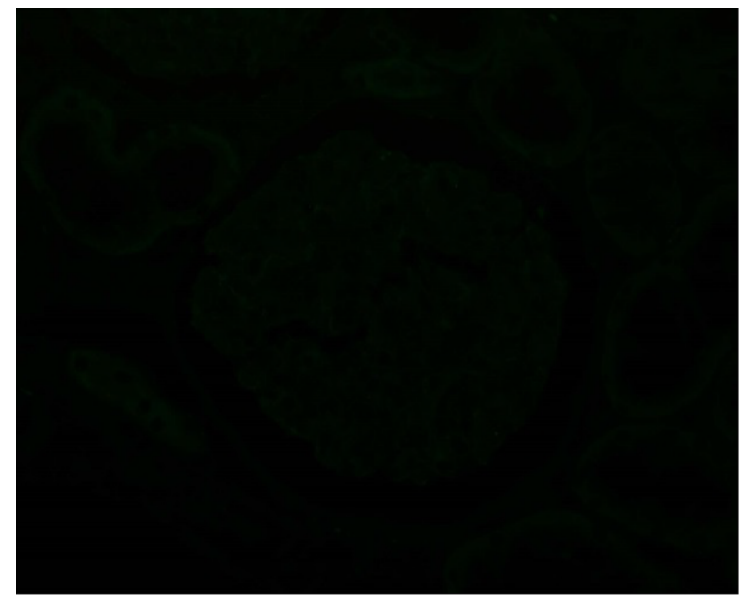

a M-type phospholipase $\mathrm{A} 2$ receptor (PLA2R)

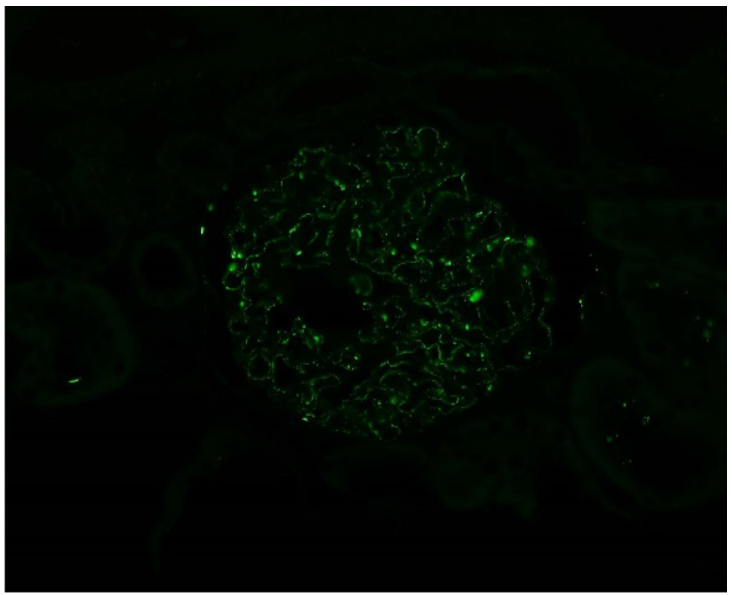

b Thrombospondin type-1 domaincontaining 7A (THSD7A)

(original magnification $\times 200$ )

Fig. 5 Immunofluorescence staining in the glomeruli. a Immunofluorescence imaging of a renal specimen from the patient did not show any enhanced granular expression of M-type phospholipase A2 receptor (PLA2R) along the glomerular basement membrane. b
Immunofluorescence image of renal specimen from the patient showing granular staining for thrombospondin type-1 domain-containing 7 A (THSD 7 A) along the glomerular basement membrane. Original magnification $\times 200$ 


\section{a Western blotting}

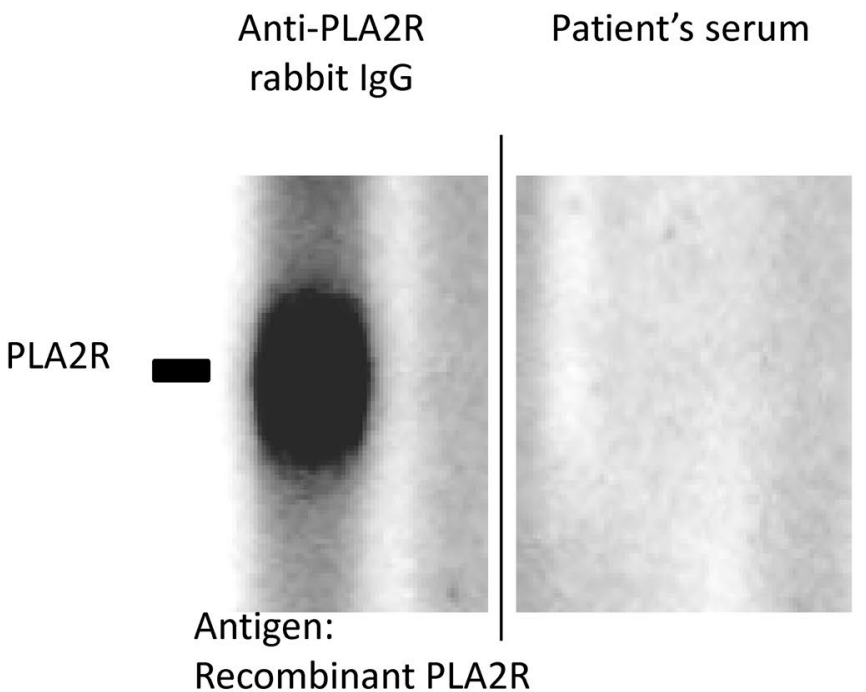

\section{Patient's Anti-PLA2R serum rabbit IgG}

\section{b Indirect IFT}

Patient's serum

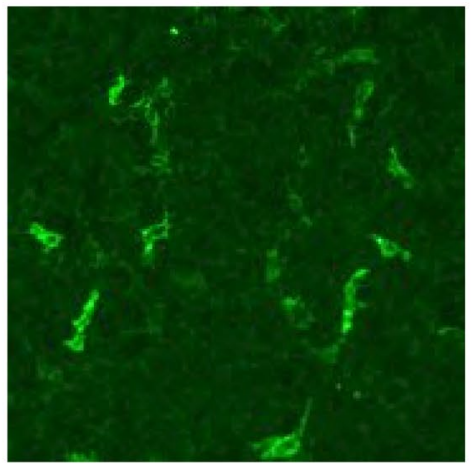

Positive control

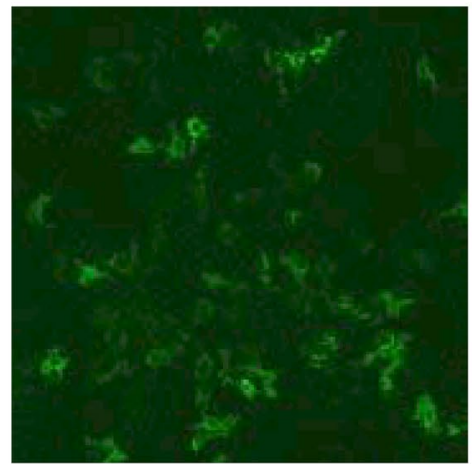

Negative control

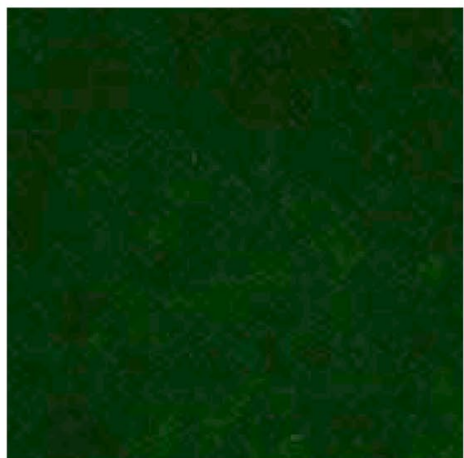

Fig. 6 Detection of circulating anti-THSD7A IgG. Anti-THSD7A antibody was measured by western blot analysis and commercial indirect immunofluorescence test (IFT). Western blot analyses of human glomerular extract (HGE) and recombinant PLA2R protein were performed under non-reducing conditions with patient's serum, using a commercial anti-PLA2R rabbit polyclonal antibody as the primary antibody. The bands were detected by chemical luminescence imaging with HRP-labeled anti-human IgG mouse monoclonal antibody and HRP-labeled anti-rabbit IgG goat polyclonal antibody. A commercial indirect IFT for anti-THSD7A IgG (Euroimmun) was performed with the patient's serum according to the manufacturer's protocol. a The image on the left shows the result of western blotting of recombinant PLA2R, expressed in HEK293 cells, under non-reducing condition with patient's serum and anti-PLA2R rabbit polyclonal antibody. The patient's serum did not recognize the recombinant PLA2R protein. The image on the right shows the result of western blotting of the HGE under non-reducing condition with patient's serum and anti-PLA2R rabbit polyclonal antibody. The patient's serum recognized a single band (white arrowhead) whose molecular weight was higher than that of PLA2R (black arrowhead) which was subsequently identified as THSD7A. b Fluorescence microscopy images obtained using a commercial indirect IFT. The patient's serum bound to the recombinant THSD7A protein on the cell surface 
Fig. 7 Clinical course and treatment of the patient. Eo eosinophil, $I g E$ Immunoglobulin E, $U P$ urine protein, $A l b$ albumin, $P S L$ prednisolone

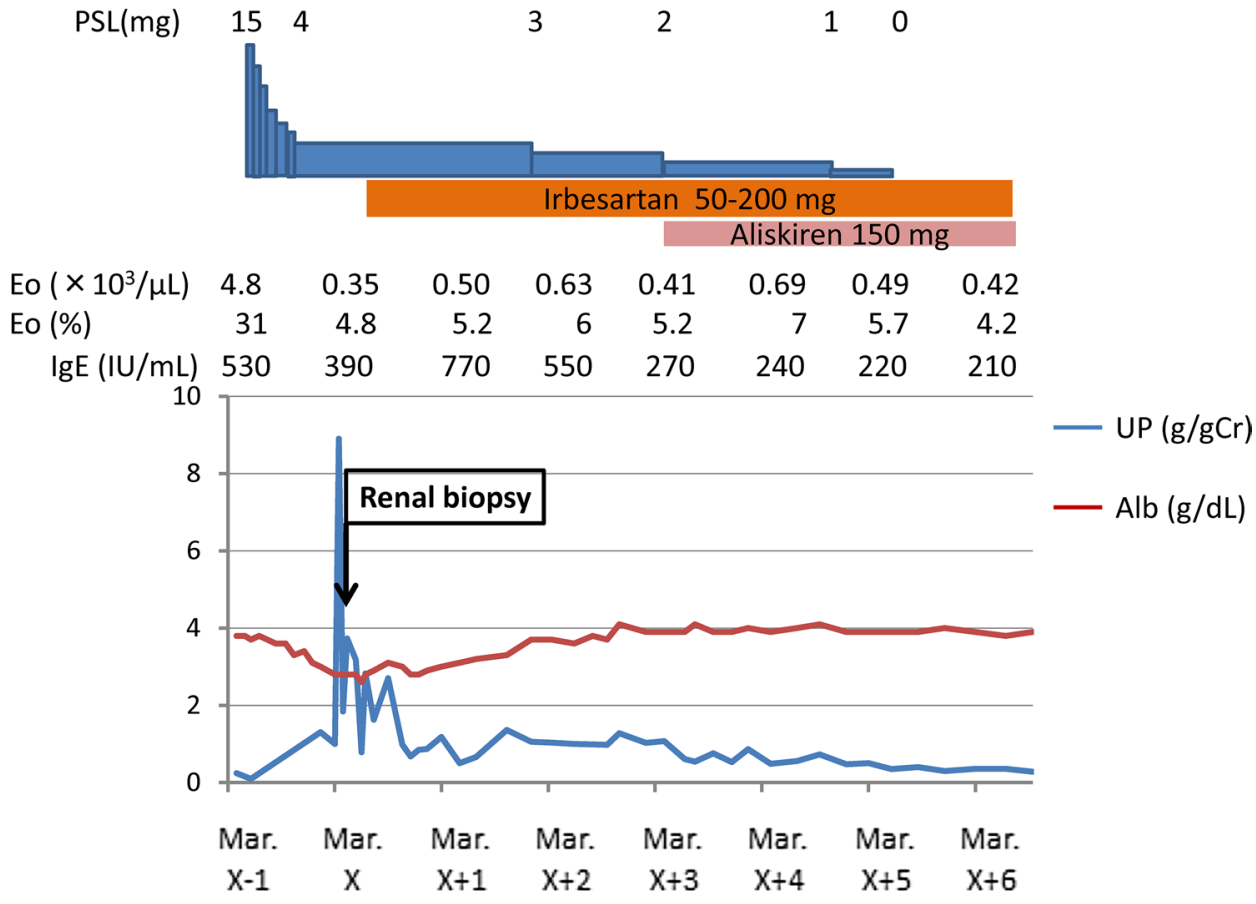

Acknowledgements We thank Shigeru Horita (Tokyo Women's Medical University Pathology Laboratory) for the enhanced THSD7A staining and their support with microscopy. We also thank the Cosmic Corporation (Japan) for providing a free trial sample of the indirect IFT from Euroimmun.

\section{Compliance with ethical standards}

Conflict of interest The authors have declared that no conflict of interest exists.

Ethical approval All the procedures performed in studies involving human participants were in accordance with the ethical standards of the Institutional and/or National Research Committee at which the studies were conducted (IRB approval number 4506) and with the 1964 Helsinki Declaration and its later amendments or comparable ethical standards.

Informed consent Informed consent was obtained from the participant included in this article.

Open Access This article is distributed under the terms of the Creative Commons Attribution 4.0 International License (http://creativecommons.org/licenses/by/4.0/), which permits unrestricted use, distribution, and reproduction in any medium, provided you give appropriate credit to the original author(s) and the source, provide a link to the Creative Commons license, and indicate if changes were made.

\section{References}

1. Beck LH Jr, Bonegio RG, Lambeau G, Beck DM, Powell DW, Cummins TD, Klein JB, Salant DJ. M-type phospholipase A2 receptor as target antigen in idiopathic membranous nephropathy. N Engl J Med. 2009;361(1):11-21.
2. Tomas NM, Beck LH Jr, Meyer-Schwesinger C, Seitz-Polski B, Ma H, Zahner G, Dolla G, Hoxha E, Helmchen U, DabertGay AS, Debayle D, Merchant M, Klein J, Salant DJ, Stahl RAK, Lambeau G. Thrombospondin type-1 domain-containing 7A in idiopathic membranous nephropathy. N Engl J Med. 2014;371(24):2277-87.

3. Beck LH Jr. PLA2R and THSD7A: disparate paths to the same disease? J Am Soc Nephrol. 2017;28(9):2579-89.

4. Akiyama S, Imai E, Maruyama S. Immunology of membranous nephropathy. F1000Res. 2019; 8:10.12688/f1000research.17589 .1.eCollection 2019

5. Iwakura T, Ohashi N, Kato A, Baba S, Yasuda H. prevalence of enhanced granular expression of thrombospondin type-1 domain-containing 7A in the glomeruli of Japanese patients with idiopathic membranous nephropathy. PLoS ONE. 2015;10(9):e0138841.

6. Hoxha E, Beck LH Jr, Wiech T, Tomas NM, Probst C, Mindorf S, Meyer-Schwesinger C, Zahner G, Stahl PR, Schopper R, Panzer U, Harendza S, Helmchen U, Salant DJ, Stahl RA. An Indirect immunofluorescence method facilitates detection of thrombospondin type 1 domain-containing 7A-specific antibodies in membranous nephropathy. J Am Soc Nephrol. 2017;28(2):520-31.

7. Ren S, Wu C, Zhang Y, Wang AY, Li G, Wang L, Hong D. An update on clinical significance of use of THSD7A in diagnosing idiopathic membranous nephropathy: a systematic review and meta-analysis of THSD7A in IMN. Ren Fail. 2018;40(1):306-13.

8. Matsumoto A, Matsui I, Namba T, Sakaguchi Y, Mizuno H, Shirayama Y, Shimada K, Hashimoto N, Doi Y, Yamaguchi S, Kubota K, Oka T, Mori D, Akiyama S, Hamano T, Mizui M, Takabatake Y, Kaneko T, Isaka Y. VEGF-a links angiolymphoid hyperplasia with eosinophilia (ALHE) to THSD7A membranous nephropathy: a report of 2 cases. Am J Kidney Dis. 2019;73(6):880-5.

9. Suzuki T, Ushimaru S, Uchida D, Watanabe S, Ichikawa D, Koike J, Mizuguchi H, Kawarazaki H, Shibagaki Y. Refractory THSD7A membranous nephropathy with severe asthma related to eosinophilia. Clin Nephrol. 2019;92(2):103-8.

10. Hara S, Tsuji T, Fukasawa Y, Hisano S, Morito S, Hyodo T, Goto S, Nishi S, Yoshimoto A, Itoh T. Clinicopathological 
characteristics of thrombospondin type 1 domain-containing 7A-associated membranous nephropathy. Virchows Arch. 2019;474(6):735-43.

11. Bissonnette B, Beaudet F. Reactive arthritis with eosinophilic synovial infiltration. Ann Rheum Dis. 1983;42(4):466-8.

12. Frigui M, Hmida MB, Jallouli M, Kechaou M, Frikha F, Bahloul Z. Membranous glomerulopathy associated with idiopathic hypereosinophilic syndrome. Saudi J Kidney Dis Transpl. 2010;21(2):320-2.

13. Obata Y, Furusu A, Nishino T, Ichinose H, Ohnita A, Iwasaki K, Taguchi T, Kohno S. Membranous nephropathy and Kimura's disease manifesting a hip mass. A case report with literature review. Intern Med. 2010;49(14):1405-9.

14. Ito S, Oda T, Matsuo A, Takechi H, Uchida T, Watanabe A, Kono T, Shimazaki H, Tamai S, Oshima N, Kumagai H. Observation of angiolymphoid hyperplasia with eosinophilia (ALHE) at three arterial sites and its association with membranous nephropathy. Intern Med. 2015;54(15):1933-9.
15. Hirayama K, Ebihara I, Yamamoto S, Kai H, Muro K, Yamagata K, Kobayashi M, Koyama A. Predominance of type-2 immune response in idiopathic membranous nephropathy. Nephron. 2002;91(2):255-61.

16. Kuroki A, Iyoda M, Shibata T, Sugisaki T. Th2 cytokines increase and stimulate B cells to produce IgG4 in idiopathic membranous nephropathy. Kidney Int. 2005;68(1):302-10.

17. Okura T, Miyoshi K, Irita J, Enomoto D, Nagao T, Kukida M, Tanino A, Kudo K, Higaki J. Kimura's disease associated with membranous nephropathy with $\mathrm{IgG} 4$ and phospholipase A2 receptor-positive staining of the glomerular basement membrane. Intern Med. 2014;53(13):1435-40.

Publisher's Note Springer Nature remains neutral with regard to jurisdictional claims in published maps and institutional affiliations. 